\title{
Teaching Strategies to Enhance Motor Skills Learning for Groups of Students: The Effects of Verbal and Visual Feedback on Performance in Pole Vault Practice
}

\author{
Chawki Derbali $^{{ }^{*}} \quad$ Fathi Matoussi $^{2} \quad$ Ali Elloumi ${ }^{3}$ \\ 1.University of Jendouba, Tunisia \\ 2.High Institute of Education and Continuing Training of Tunis, Virtual University of Tunisia \\ 3.Laboratory TEC, University of Paris Descartes, Paris, France
}

\begin{abstract}
This paper contributes to enhancing a comparative study on a creative conduct of teaching method in physical education sessions. We search for determine the evolution of teacher representations related to the understanding of the particular practice of pole vaulting and its teaching by integrating a computer-video artifact into an educational environment. This study was done in two graduate classes of high school including $(\mathrm{N}=44)$ students. These are two groups; aged between 15 and 18 (One group of students was provided with a verbal and gestural communication, while the other was asked to view an artifact video). The pole vole learning cycle consisted of 14 sessions, divided between two sessions per week. The findings were consistent with the difference between methods of teaching in line with tasks of learning. Through this experiment and lessons feedbacks, we have been able to conclude that the use of the Computer Communication Technology and precisely of the video image artifact, was source of progression of the motor learning for the large majority of the students from the all group study. This research is opened to understand and appreciate how to best design video lectures that encourage learning and developing knowledge.
\end{abstract}

Keywords: physical education, artifact video, feedback, motor learning, skills

DOI: $10.7176 / \mathrm{JEP} / 10-7-06$

Publication date:March $31^{\text {st }} 2019$

\section{Introduction}

In recent years, the value of sport has evolved in physical education programs (Bailey, 2018; Chen et al., 2017; Hastie \& Wallhead, 2015 ; Solmon, 2015). Indeed, the use of physical activities and sports (PAS) at school is highlighted as a teaching discipline and as an important environment for physical activity promotion (MayorgaVega et al., 2018). It is becoming difficult today to recommend an integration of sports practices without it being reproved by a part of the community. So, what is the logic behind the choice of teachers' practices today? Several researches have already poured out on the choices of the teachers in bodies of sporting practices. Many studies bring together that one of the aims of physical education (PE) is to develop social skills such as cooperation, teamwork, and mutual helping among students. Or, on the contrary, on the moral value of physical activity: body and soul (Carr, 2010). These studies provide a global and stable view of teachers' choice of PAS. They reveal the importance of this sport standard, traditional in PES. The new analyzes show that the changes are related to the context that infers vigorous constraints. The social context of sport on transforming communities (Spaaij et al., 2016), or internal, as the institutional constraints (Poggi-Combaz, 2002a) are perceptible through a marked distance to the sport practice and physical self-perception (Derbali et al., 2009, 2008; Leziart, 2007) or a delay of introduction new activities (Loret, 1996). Classification analyzes are aimed at terminating dominant rules that are required in physical education and sports (PES). These constraints tend to determine a relative homogeneity of the teachers' choices. While, beyond these constraints that balance programming and tend to standardize them, teachers are differentiated on the choices of PAS. Would the technical skills of pole vault hiding a heterogeneous educational use of bodily practices? What are the meanings of these different uses of pole vaulting in PES?

Firstly, assessment is, on the one hand, ubiquitous in the school system and poses many problems of justice (Campbell, 2010). On the other hand, unequal sexual gender relations are still present today in society workplace (Stamarski \& Son Hing, 2015). It's the same at school and in PES. In the latter, the grades of boys are generally higher than those of girls. This scoring gap poses, for example, a problem of legality between students in PES exams. Here, the answer is not limited to a difference in motor abilities. Several elements interfere, such as the predominance of male activities, the entry into the foreign activity of girls, the scales that are not very sensitive to genetic differences. Whereas previous studies focusing on what the student thinks are rarer and do not answer the questions that challenge us: do students perceive inequalities between the sexes? Do they feel an injustice in PES assessment? The school, vector of equality between the sexes, participates at the same time in the construction of gender differences. In school, boys and girls experience very different socialization (Edwards et al., 2003).

These consist of behavioral coherences combined with evaluation, organization, influencer design and management, effort and retrospection in a particular practice. In addition, changes in educating PE could be 
desirable in witch; sense of coherence is supposed to be the major indicator of health-oriented behavior (Klunder \& Lipowski, 2014). The strategic choice leads to a variation in the perceived risk intensity of the activity or importance associated with the situation. It finds its origin in the value of achievement of the task. But the strategy adopted will not always result in success (Famose, 1996). This work section defines two particular motivational strategies for effectively managing the fulfillment situations. First, defensive pessimism (Norem \& Cantor, 1986b) is used when the apprehension of failure is strong but the desire to succeed is important. To rely on the strategy mentioned allowing us to develop the negative effects, by the amount of effort provided. On the one hand, to protect oneself against a possible failure, while preparing oneself, on the other hand, to motivate oneself by intensifying the effort in order to succeed the task and to increase the pleasure to have properly intervene (Bastianello et al., 2014; Derbali, 2010) . In contrast, the strategy of optimism (Norem \& Cantor, 1986b) is used by people with high self-esteem, low anxiety, and the possibility of failure. Also, optimism may influence mental and physical well-being by the encouragement of a healthy lifestyle as well as by adaptive behaviours, associated with greater flexibility and problem-solving capacity (Conversano et al., 2010). The use of defensive pessimism strategy (Canedo et al., 2018) may involve students with either low or high self-esteem.

The outcome is often associated with a sense of control and the perception that students have of their abilities is quite close to reality. In addition, teachers must have expectations regarding the teaching of PES in general and pole vaulting in particular. More specifically, the educational reform reviews the objectives and contents of the teaching, at all levels and for each discipline, decreeing fundamental objectives and the minimum of the compulsory contents to be achieved by the students. In this general context, physical education in Tunisia has undergone significant changes, such as the looking of its status as an official subject in PES, which concerns athletic education: triple jump, height jump that say for the integration of the jump at the pole by treating it in a global context of jumping in fun, technical and educational form.

\section{Theoretical and problematic positioning}

The didactic approach supported in this study, considers that the student is an actor engaged in a system of learning action. This approach could be in agreement with a sociology that assumes individual identity and social identity coexist (Elias, 1991), within the framework of motor praxeology. In this context of motor action Parlebas (1991) presents an illustrative model of motor action and notes a classification of motor situations. For example, Teachers build a learning context encouraging students to actively engage in and take ownership of their learning experiences, a setting stimulating learners to imagine deeply about how they might apply what they are learning to their envisaged practice (Moate \& Cox, 2015). When the student is engaged into motivated sport practice, he is considered to be at the center of an interactional system by interacting with both his peers and his physical environment. In the framework of the work presented here, not only the degree of motor interaction between peers is the only determining factor in the learning situations proposed to the experimental group, but at the same time the intervention of the external regulator as support for the learning phases of the jump by pole, in the logic of the motor action and the characteristics of the activity.

The various jumps with the pole are part of the learning situations practiced in the physical education class, soliciting imagery self-observation, video visualization and the intervention of the educator, as well as the modalities of learning. According to the praxic and psychological approach, relational modalities described as "psychomotor" are identified (Parlebas, 1991). They put the learner in a situation of diminished interaction with others on a motor level. We note here that the particular practice of pole vaulting can be considered psychomotor activity (Derbali et al., 2017c). In the class of psychomotor situations, none of the given motor tasks requires the participation of others to be accomplished. However, notwithstanding the absence of praxic interaction, several relational possibilities still exist. Thus, we mention three simultaneity, alternation and motricity in isolation. The first two are generally called "comotrices" because they are located together, in the same space with several participants, without the action of each of them being immediately influenced in its functional achievement, by the behavior of others (Derbali et al., 2017a; Parlebas, 1999). They offer students to act in a common space and time. They represent the category of situations of active co-presence. Simultaneously, the tasks to be performed start from a common starting signal for 2 or more students and are placed for anyone in symmetrical places, whether they are parallel or sharing around an arbitrary axis of symmetry. Thus, varied jumping courses in parallel are a translation of this learning mode. Here, it is in pole vault that this relational modality of practice is maintained. The temporalities of the observation, with the help of the teacher, which admit the visualization of the benefit of others and of argumentative language activity, participate in this mode of learning. During isolated motor skills, practitioners intervene singly to perform the tasks requested. Isolated situations correspond to a form of passive co-presence. Specific examples of the procedure and instructions offered to students will be detailed when describing learning tasks in pole vaulting. Thus, we discuss feedback interactions and coupled video observation of gender-differentiated treatment as a teaching-learning tool. 


\section{Observation and feedback}

\subsection{Video observation during action in motor learning}

To explain learning in the field of physical education video could be a sophisticated way for the understanding and correction of student movement. In the school context of Pole Vault learning, we invest in the observation of student behavior and the use of video images. The filmed learning sequences could produce figurative forms. The interest of this study is first, to study the reliability of the implementation of the video tool in a cycle of teaching and learning the practice of pole vaulting. Then, determine the effectiveness of feedback on learning through the video image.

According to Schmidt (1993), feedback is information about the difference between the state of an objective and the performance. Through feedback, the learner can grasp the difference between what he actually built and what he had to accomplish. To ensure that the task is learned and to guarantee the acquisition, the learner must know the course of the action and its result (Salmoni et al., 1984). Feedbacks are categorized into two categories. Intrinsic feedback, derived mainly from the own perceptual channels, vestibular and proprioceptive systems, and extrinsic feedback is mainly managed by the educator, coach, and teacher in visual form such as, video footage (Schmidt, Lee, 1999; Salmoni et al., 1984). The tautology of meaning in these two types of feedback does not diminish motor learning (Schmidt, 1993). However, the feedback concerns the knowledge of the result of the action and the knowledge of the performance. First, if the learner can know if he has succeeded or failed, it is because it does not require great precision. This need can usually be obtained through intrinsic feedback. Then, in the case where the information on the result has to be more precise or if the practitioner does not have the potential to distinguish by itself the result of his action, it may be necessary to resort to external reinforcement through extrinsic feedback. In fact, at the beginning of the apprenticeship, the practitioner does not know how to use the potential of his proprioceptive system, which is an important clue to information about the progress of the action (Magill, 1993). Thus, knowledge of performance may be considered more difficult to exploit by the novice, as it seems to be more effective at ensuring the acquisition of complex tasks involving a variety of movements (Young \& Schmidt, 1992).

In our case, the result knowledge would not give sufficient information on the inter-segmental coordination, air balance and control of the pole, which characterize this type of jump task. To explain this fact by the necessity for the practitioner of motor skills not only open according to the space but also closed, for what it requires to master a form from the quantitative point of view and certainly qualitative in order to be informed on the quality of its performance. For this type of task, the knowledge of performance is similar to a form of knowledge of the result (Young \& Schmidt, 1992). In general, consolidated and well-argued feedback assists learning in a variety of ways. An important motivational role could be translated into greater and more sustained engagement by the learner over time (Salmoni et al., 1984). Another supportive role in producing good performance by positive reinforcement of good deeds (Salmoni et al., 1984, Schmidt, 1993). The motor models brought to suckle will thus be favored over those leading to failure. This provides the learner with information about the outcome or course of action (Salmoni et al., 1984, Schmidt, 1993). To ensure the development of the necessary cognitive and motor skills and to interpret and correct its movement, the usefulness of this support is precision and support for the improvement of learning by stating the gaps and actions to be repaired. During the next intervention, the mechanisms facilitating learning would be identical for all types of feedback. Still, at the beginning of the learning, the subject needs to be oriented by a frequent feedback, but that it must gradually be reduced to oblige the learner to use his own sensory perceptions. The need for frequent feedback depends not only on the level of the student but also on the corresponding difficulty of the work and the time of the action.

\subsection{Video feedback}

The understanding of a motor behavior in pole vault requires an observable processing of information. This requires the visualization of the result to know the performance. Hence, we need for external feedback considering the video as a source of information on the behavior of the practitioner to view his own performance directly at the end of it and thus compare it to the mental representation of the movement he had built following the demonstration or the instruction. Subsequently, we presented that this comparison was a useful way to refine this mental representation and help as a support for the programming of the next attempts.

The video provides elements of motion that can be observed and corrected on the basis of visual information (Schmidt 1993; Bandura, 1976). Little research has supported the use of video in the context of school physical education. It seems that this tool is only rarely used by physical education teachers. Guadagnoli et al. (2002) discuss the efficacy of the proper exploitation of time and available resources required for the use of video. In addition, some studies highlight the importance of repetition for the acquisition of a task (Bonney et al., 2017; Bosse, 2015; Guadagnoli et al., 2001). Indeed, the time reserved for the feedback and the analysis of the movement must not be in spite of the practice time. Then Swinnen (1996) adds that the teacher of PES is responsible for optimizing the conditions of realization of the task and he is not a distributor of feedback, in order to facilitate the emergence and the repetition of the motor response more appropriate. The feedback through the film sequences 
produces progression and improvement of the learning of complex tasks in students not only at the level of acquisition of morphokinesis (Caroll \& Bandura, 1982) but parallel to the level of equilibration and adaptability. This means furthermore gives an advantageous malleability of use for the learning of the action. For example, the movement can be observed more than once and can be delayed on a specific element to be examined.

The reading of body characteristic movement in EPS in a given environment is most often complex because very different depending on the individual. The verbal regulations of the teacher should almost all be different and in this, the video is a very privileged tool to access the different information given by the bodies of individuals in motion. It ensures very realistic representations thanks to the coupling of the visual and the auditory, which implies that it is very adapted to the motor learning of the practice of the Physical and Sports Education. This study seeks to confirm the hypothesis that video feedback facilitates the learning of new complex skills as part of a pole vault cycle. This learning will be strengthened because the video magnifies learners' motivation and allows them to better distinguish the differences between the form and the form (Schmidt, 1993). The crucial objective of providing video feedback is the understanding of the function of the error and consequently the identification of student successes. The verbal correction of the teacher will allow students to situate in the motor learning where the errors and successes are and thus set up a guide to more appropriate and more effective movements.

\section{Method}

\subsection{Experimental protocol}

We seek to determine the evolution of teacher representations related to the understanding of the particular practice of pole vaulting and its teaching by integrating a computer-video artifact into an educational environment. This study was done in two graduate classes of high school. These are two groups, aged between 15 and 18 (a "video group" and a "non-video group"). These are motivating and active classes where we will find parity between girls and boys including between 23 and 21 students per class. The pole vole learning cycle consisted of 14 sessions, divided between two sessions per week, which planned on Thursdays and Saturdays from 10 am to 11 am for first class and from 11 am to 12 am for second class. The sessions took place in the gym and in the sand jumper. To establish a comparative study between two teaching methods (with and without video), it required to set up two heterogeneous groups. This is what we organized after the predictive assessment at the first session, while adjusting the detailed learning content for the students during this pole vault cycle. The objective of the learning cycle was to transmit motor, affective and cognitive learning with strategies that postulate the motivation, control and support of student autonomy during pole vaulting while having the most appropriate didactic and pedagogical situations. The diagnostic assessment in the beginning of the cycle and the summative evaluation at the end of the cycle would be done by the teacher, concern pupils' skills and their performance levels. Thus, we will examen the technical and motor level and we will hold progress on the level of motor skills and their performance to measure. Finally, we will identify the evolution of students in the practice of pole vaulting.

In the middle of the session, we integrate Learning situations that will allow the language and gestural corrections of the teacher for one group, whereas for the other group, the video will allow relying on the students' short-term memory to visualize their performances to which verbal corrections will be added as well as the debate of ideas. It was important that the sessions be completely identical in both the video and non-video group. We to ensure that girls and boys as students, of both classes receive the same instruction, games, education task and exercises. The goal is that the experimentation is done under similar conditions so as not to distort the results. Our exchanges upstream and throughout the cycle were numerous to stay in phase and ensure that there is the least possible lag in the instructions and corrections. We also made sure to start each session with the class group and finish each session in the same way to maintain unity and not break the overall dynamics of the class (see Figure $1)$.

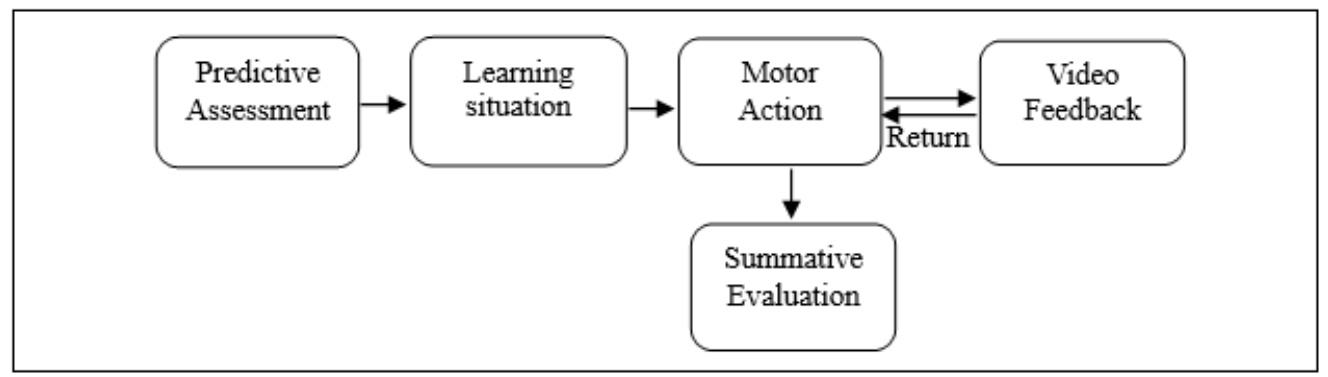

Figure 1. Structure of sessions of a teaching-learning cycle with video artifact

4.1.1. Protocol of action with both classes

To test the reliability of the tool, we have implemented exactly the same protocol. We had two classes for this investigation. We separated each class into two heterogeneous groups following the first session which was the diagnostic assessment. One of these groups will receive instruction using video supported by verbal and gestural 
corrections, while the other group will only benefit from verbal and gestural corrections (without video). Each session of the cycle will be broken down as follows:

- Situation 1: Group warm-up class.

- Situation 2: Placing the technical element to work on the session in the form of jumping and group jumping class games.

- Situation 3: Technical workshops in group, with for a group the use of the video.

- Situation 4: Placing the technical element to work on the session in the form of jumping and group jumping class games.

The video workshop accompanied by educational exercises is certainly motivating because it happens in front of the camera. Again, the use of the video applies to all sessions, for duration of around 15 minutes. The material used to ensure video observation is as follows: A computer, a camcorder, a FireWire cable and a "Dartfish" software for managing the reading of the student's passage. In the field of the camera runs the workshop "video". The students perform their exercises at first. Then, in a second time, they go behind the computer to view the video of their performances. Then, each student makes an immediate return and starts the exercise again correcting their mistakes once the visualization is done. This operation allows students to increase their motivation, to have an immediate knowledge of their performance and to make visible the verbal and gestural advice of the teacher. They will gradually self-evaluate with a real look at their benefits. This approach allows the teacher to make sense of the different advice given to students.

A similar structure was developed for all sessions with the exception of the Predictive Assessment at the first session and the Summative Evaluation at the 12th session. The interest of the study is to offer these students benchmarks to facilitate and improve motor skills. However, the content is distributed according to the logic of the cyclical programming and according to the objective of each session of ludomotor learning.

\section{SHEET OF A PHYSICAL EDUCATION LESSON}

\section{Operational Objective of the Session}

Classe :

Séance :

Effectif :
Describe in a univocal way the content of the pedagogic purpose

(know how to do and know how to be)
Date :

Horaire :

Durée :

Matériel : success criteria

\begin{tabular}{|c|c|c|c|c|c|}
\hline Parties & Sub-objectives & Lesson Content & Schema & Time & Criteria for success \\
\hline $\begin{array}{l}\text { 1. TAKING } \\
\text { CONTROL OF } \\
\text { THE CLASS. } \\
\text { "Lesson start" }\end{array}$ & $\begin{array}{l}\text { Be attentive to the presentation } \\
\text { of the work, understand the } \\
\text { lesson rules, remember what } \\
\text { have been experienced, and be } \\
\text { mentally ready to practice... }\end{array}$ & $\begin{array}{l}\text { - Reception and grouping, the call, the sartorial control; } \\
\text { - Reminder of what we experienced in the previous session and lesson work } \\
\text { presentation } \\
\text { Presentation of the task, device, groups, roles, instructions ...; } \\
\text { - Development of the personal project ... }\end{array}$ & \multirow{4}{*}{$\begin{array}{l}\frac{\text { Descriptive diagram }}{\text { of a device }} \\
\frac{\text { "A beautiful scheme }}{\text { is better than a long }} \\
\text { speech" } \\
\\
\text { Expressive } \\
\text { Diagram: } \\
\text { Organized, Detailed } \\
\text { and Clear }\end{array}$} & \multirow{4}{*}{ 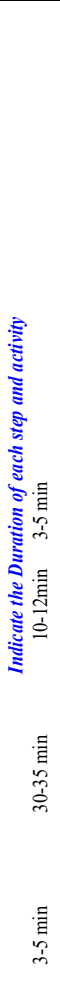 } & 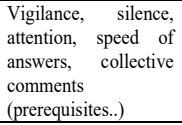 \\
\hline $\begin{array}{l}\text { 2. STARTING } \\
\text { THE LESSON. } \\
\text { " Warming up " }\end{array}$ & $\begin{array}{l}\text { Prepare muscles and joints for } \\
\text { physical effort and activity, } \\
\text { activate circulatory and } \\
\text { respiratory functions, and } \\
\text { protect against incidents and } \\
\text { injuries. "Prepare the } \\
\text { organization for learning and } \\
\text { the efforts of the session" }\end{array}$ & $\begin{array}{l}\text { - Physiological activation of the body's functions. } \\
\text { - Muscle tension adjustment by contraction and stretching adapted to the type of } \\
\text { effort seeking the muscular amplitude. } \\
\text { - Joint mobilizations most requested by the APS. } \\
\text { - Progressive warming from general to APS specific } \\
\text { - Games adapted to the warm-up and introductory to the lesson. }\end{array}$ & & & $\begin{array}{l}\text { - Sudation of the } \\
\text { body; } \\
\text { - Face redness; } \\
\text { - Body sweats } \\
\text { - Breathing quality; } \\
\text { Heart rate (beats / } \\
\text { min) } \\
\text { - Fun of the game } \\
\text { (happy/activated) }\end{array}$ \\
\hline $\begin{array}{l}\text { 3. LESSON } \\
\text { BODY } \\
\text { "Learning } \\
\text { Situations" }\end{array}$ & $\begin{array}{l}\text { Necessary progression into } \\
\text { "sub-objectives" to achieve the } \\
\text { objective of the lesson. } \\
\text { They must be formulated at } \\
\text { using an action verb } \\
\text { inducing behavior } \\
\text { observable. } \\
\text { What the student needs to } \\
\text { achieve }\end{array}$ & $\begin{array}{l}\text { Learning Situation No. } 1,2 \text { etc. } \\
\text { - Device: environmental management and grouping of students; } \\
\text { - Procedure: procedure and instructions; } \\
\text { - Achievement criteria: how to do it; useful actions, operations to be done to } \\
\text { succeed; } \\
\text { - Rules of action link and articulate the criteria of achievement; - "what are the } \\
\text { conditions and how to do it concretely? "- data to the student or researched } \\
\text { (practical knowledge); } \\
\text { - Evolutions: revive student interest, change behaviors and strategies; challenge } \\
\text { of pleasure and challenge. } \\
\text { - Regulations / adaptations / extensions: Possibilities of simplification or } \\
\text { complexity of the situation or task } \\
\text { - Discovery situation - situation-problem (identify where the student is, in } \\
\text { relation to the objective. } \\
\text { - Structuring situation - situations-problems with evolutions, proposing } \\
\text { variants, to help the student to discover the rules of action necessary for his } \\
\text { success. } \\
\text { - Reinvestment situation -Reuse the action rules discovered in other situations }\end{array}$ & & & $\begin{array}{l}\text { Terminal performance } \\
\text { requirements } \\
\text { criterion, as a } \\
\text { favorable result. it is } \\
\text { the visible } \\
\text { manifestation of the } \\
\text { attainment of goal. } \\
\text { Observable, } \\
\text { Quantifiable and } \\
\text { Verifiable Criteria } \\
\text {-Inscribed in the } \\
\text { device: impulse on the } \\
\text { board } \\
- \text { Abstract: run } \\
\text { without slowing down } \\
- \text { Quantifiable: } \\
\text { successful } 6 \text { times / of } \\
10 \text { ralation to a } \\
\text { - In relar } \\
\text { criterion for carrying } \\
\text { out the action }\end{array}$ \\
\hline $\begin{array}{l}\text { 4. RETURN TO } \\
\text { CALM. } \\
\text { "End of } \\
\text { lesson" }\end{array}$ & $\begin{array}{l}\text { Aappease the body towards the } \\
\text { state of rest and to appropriate } \\
\text { itself by defining its feelings } \\
\text { verbalizing emotions, actions' } \\
\text { rules and security }\end{array}$ & $\begin{array}{l}\text { - Physiological recovery, stretching, relaxation and relaxation: gradual return to } \\
\text { calm (do not go directly from the race to a static position); to lie down and listen } \\
\text { to the music. } \\
\text { - Reminder of what has been done, learned and met; Collective presentation of } \\
\text { instructions and supervision } \\
\text { - Collective lesson report, storage of equipment, re-dressing }\end{array}$ & & & $\begin{array}{l}\text { Check normal cardiac } \\
\text { and respiratory rates; } \\
\text { body relaxed and } \\
\text { elongated, at ease not } \\
\text { out of breath. }\end{array}$ \\
\hline Lesson Analysis & $\begin{array}{l}\text { Envisager } \\
\text { Mettre en } \\
\text { Mettre en }\end{array}$ & & & & \\
\hline
\end{tabular}

Figure 2. Technical elaboration of a physical education sheet lesson 


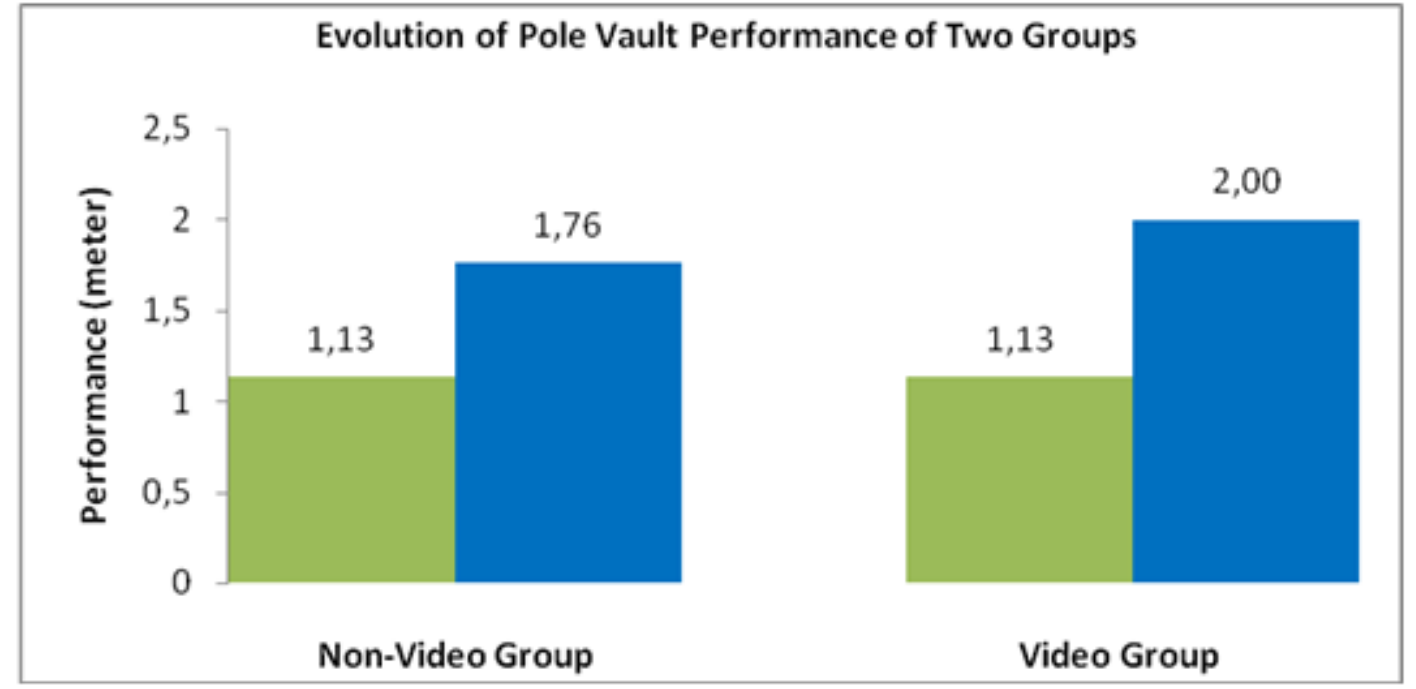

Figure 3. Evolution of motor performance in pole vault of video and non-video groups.

Table 1. Descriptive statistics of young boys' performance and progress by groups

\begin{tabular}{cccccc}
\hline Boys & Initial Performance & Final Performance & Progression (meter) & Progression (\%) & Group (N=23) \\
\hline 1 & 1.70 & 3.50 & 1.80 & 51.42 & Video \\
2 & 1.40 & 2.40 & 1.00 & 41.66 & Video \\
3 & 1.30 & 2.25 & 1.05 & 46.66 & Video \\
4 & 1.30 & 2.20 & .90 & 40.90 & Non video \\
5 & 1.30 & 2.15 & 1.15 & 53.48 & Video \\
6 & 1.30 & 2.10 & .80 & 38.09 & Non video \\
7 & 1.20 & 2.05 & .85 & 41.46 & Video \\
8 & 1.10 & 2.05 & .95 & 46.34 & Video \\
9 & 1.10 & 2.05 & .95 & 46.34 & Video \\
10 & 1.00 & 2.05 & 1.05 & 51.21 & Video \\
11 & 1.20 & 2.05 & .85 & 41.46 & Video \\
12 & 1.10 & 2.05 & .95 & 46.34 & Video \\
13 & 1.20 & 2.00 & .80 & 40 & Video \\
14 & 1.10 & 2.00 & .90 & 45 & Video \\
15 & 1.20 & 2.00 & .80 & 40 & Non video \\
16 & 1.20 & 2.00 & .80 & 40 & Non video \\
17 & 1.00 & 1.90 & .90 & 47.36 & Non video \\
18 & 1.30 & 1.90 & .60 & 31.57 & Non video \\
19 & 1.20 & 1.80 & .60 & 33.33 & Non video \\
20 & 1.30 & 1.80 & .50 & 27.77 & Non video \\
21 & 1.20 & 1.80 & .60 & 33.33 & Non video \\
22 & 1.30 & 1.80 & .50 & 27.77 & Non video \\
23 & 1.20 & 1.40 & .20 & 14.28 & Non video \\
\hline
\end{tabular}

However, the progress in meters is not indisputably demonstrative of the real improvements of the pupils since they do not begin all with the same level of practice. In addition, we considered the percentage of individual progression between the diagnostic assessment and the summative evaluation. As a result, we could compare students not with their performance, but with their percentages of progressions. Tables 1 and 2 below were therefore more significant for the students' situation in terms of their place in the groups. He presented very clearly the contribution of the video tool in the progression of the students. Thus, the average percentage of progression observed varied for the video group from 29 to 53\%, whereas for the non-video group, it ranged from 12 to $47 \%$, showing a greater homogeneity in the video group compared to the non-video group. But we especially remember that the average percentages of the two classes are almost different. 
Table 2. Descriptive statistics of girls' performance and progress by groups

\begin{tabular}{cccccc}
\hline Girls & Initial Performance & Final Performance & Progression $(\mathrm{m})$ & Progression $(\%)$ & Group $(\mathrm{N}=21)$ \\
\hline 1 & 1.40 & 2.45 & 1.25 & 51.02 & Vidéo \\
2 & 1.10 & 2.00 & .80 & 40 & Non vidéo \\
3 & .90 & 1.80 & .70 & 38.88 & Vidéo \\
4 & .95 & 1.75 & .80 & 45.71 & Vidéo \\
5 & 1.00 & 1.70 & .70 & 41.17 & Non vidéo \\
6 & 1.00 & 1.70 & .70 & 41.17 & Vidéo \\
7 & 1.00 & 1.70 & .70 & 41.17 & Vidéo \\
8 & 1.20 & 1.70 & .50 & 29.41 & Vidéo \\
9 & 1.00 & 1.70 & .70 & 41.17 & Vidéo \\
10 & 1.00 & 1.70 & .80 & 47.05 & Vidéo \\
11 & 1.00 & 1.70 & .70 & 41.17 & Vidéo \\
12 & 1.00 & 1.70 & .70 & 41.17 & Vidéo \\
13 & .95 & 1.65 & .70 & 42.42 & Vidéo \\
14 & 1.00 & 1.65 & .65 & 39.39 & Non vidéo \\
15 & 1.10 & 1.65 & .55 & 33.33 & Non vidéo \\
16 & 1.00 & 1.65 & .65 & 39.39 & Non vidéo \\
17 & .80 & 1.60 & .60 & 37.50 & Non vidéo \\
18 & 1.30 & 1.60 & .30 & 18.75 & Non vidéo \\
19 & .85 & 1.60 & .75 & 46.87 & Non vidéo \\
20 & 1.10 & 1.60 & .50 & 31.25 & Non vidéo \\
21 & 1.10 & 1.25 & .15 & 12 & Non vidéo \\
\hline
\end{tabular}

Note. m: meter, - Pole vault performance measured by meter;

$\%$ : Parentage of performance progression;

$\mathrm{N}=21$ : Number of students.

All students, whether in the video group or the non-video group, have improved their performance during the pole vault learning cycle, as they have no experience in this practice and it was their first participation. While, we find that all students in the video group have a higher percentage progression than students in the other group. The table 3 below summarizes the results of each group with different statistics.

Table 3. Averages, standard deviations, and percentages of performance and progress

\begin{tabular}{|c|c|c|c|c|c|}
\hline & & Initial Performance (m) & Final Performance $(\mathrm{m})$ & Progression $(\mathrm{m})$ & Progression (\%) \\
\hline \multirow[t]{4}{*}{ Video Class } & $M$ & 1.13 & 2.00 & 0.89 & 43.82 \\
\hline & $E-T$ & 0.18 & 0.40 & 0.26 & 5.21 \\
\hline & Min. & 0.90 & 1.65 & 0.50 & 29 \\
\hline & Max. & 1.70 & 3.50 & 1.80 & 53 \\
\hline Non-Video & $M$. & 1.13 & 1.76 & 0.61 & 33.90 \\
\hline \multirow{3}{*}{ Class } & $E-T$ & 0.15 & 0.23 & 0.20 & 9.52 \\
\hline & Min. & 0.80 & 1.25 & 0.15 & 12 \\
\hline & Max. & 1.30 & 2.20 & 0.90 & 47 \\
\hline Video Group & $M$. & 1.22 & 2.21 & 1.02 & 45.75 \\
\hline \multirow[t]{3}{*}{ Boys } & $E-T$ & 0.18 & 0.42 & 0.26 & 4.28 \\
\hline & Min. & 1.00 & 2.00 & 0.80 & 40 \\
\hline & Max. & 1.70 & 3.50 & 1.80 & 53 \\
\hline \multirow{4}{*}{$\begin{array}{l}\text { Non-Video Group } \\
\text { Boys }\end{array}$} & $M$. & 1.22 & 1.88 & 0.65 & 34 \\
\hline & $E-T$ & 0.09 & 0.20 & 0.21 & 8.85 \\
\hline & Min. & 1.00 & 1.40 & 0.20 & 14 \\
\hline & Max. & 1.30 & 2.20 & 0.90 & 47 \\
\hline Video Group & $M$. & 1.03 & 1.77 & 0.75 & 41.72 \\
\hline \multirow{3}{*}{ Girls } & $E-T$ & 0.14 & 0.22 & 0.18 & 5.51 \\
\hline & Min. & 0.90 & 1.65 & 0.50 & 29 \\
\hline & Max. & 1.40 & 2.45 & 1.25 & 51 \\
\hline Non-Video & $M$. & 1.03 & 1.63 & 0.56 & 33.80 \\
\hline Group & $E-T$ & 0.14 & 0.17 & 0.20 & 10.70 \\
\hline \multirow[t]{2}{*}{ Girls } & Min. & 0.80 & 1.25 & 0.15 & 12 \\
\hline & Max. & 1.30 & 2.00 & 0.80 & 47 \\
\hline
\end{tabular}

Note. m: meter, - Pole vault performance measured by meter;

$\%$ : Parentage of performance progression;

$\mathrm{N}=44$ : Number of students. 
Statistical data with a student test showed us a comparison of two averages for experimental groups (see Figures 4 and 5). It is calculated with the average performances, according to the two groups (Video or Non-Video) and on both tests. We can see results below.

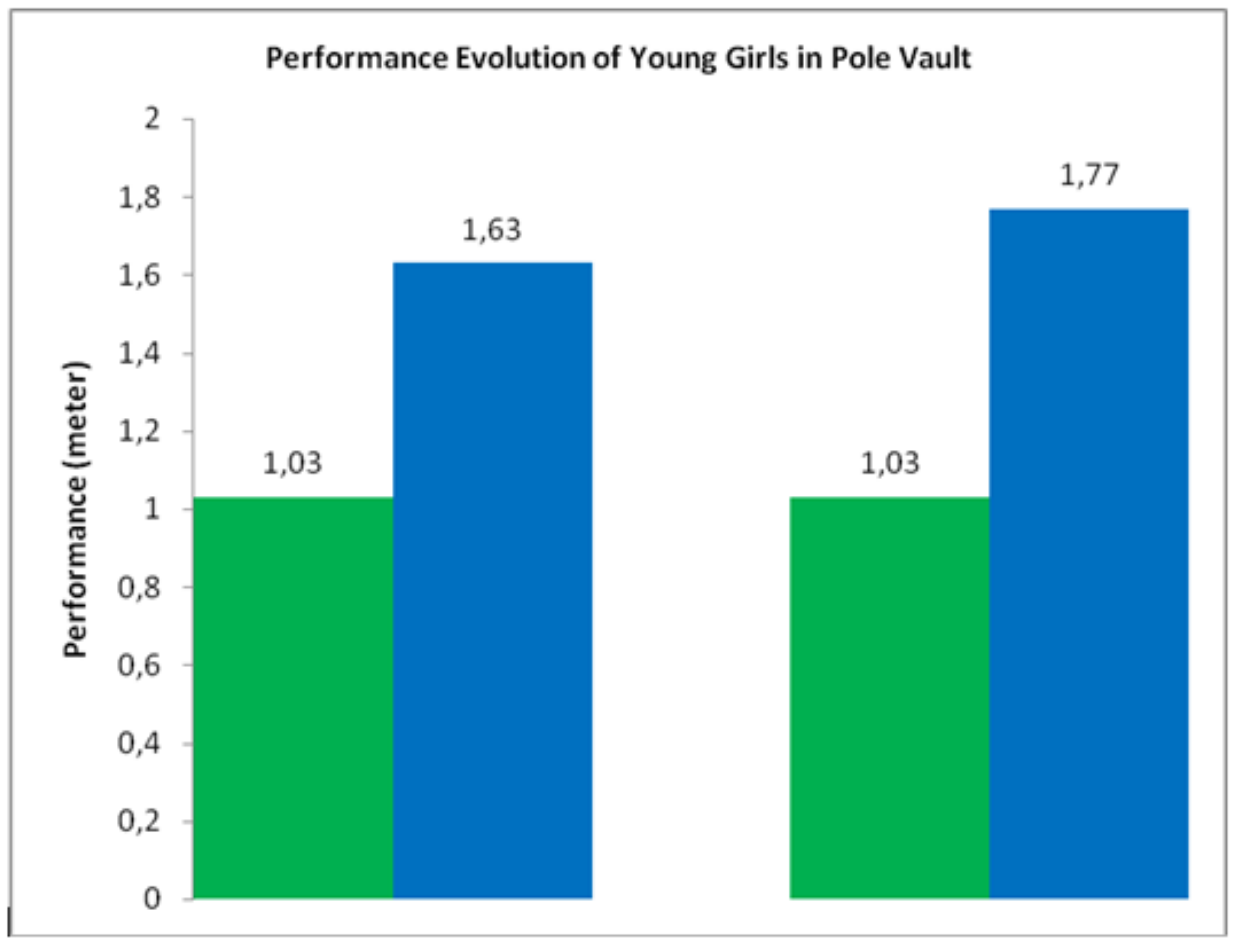

Figure 4: Evolution of driving performance in pole vault of girls

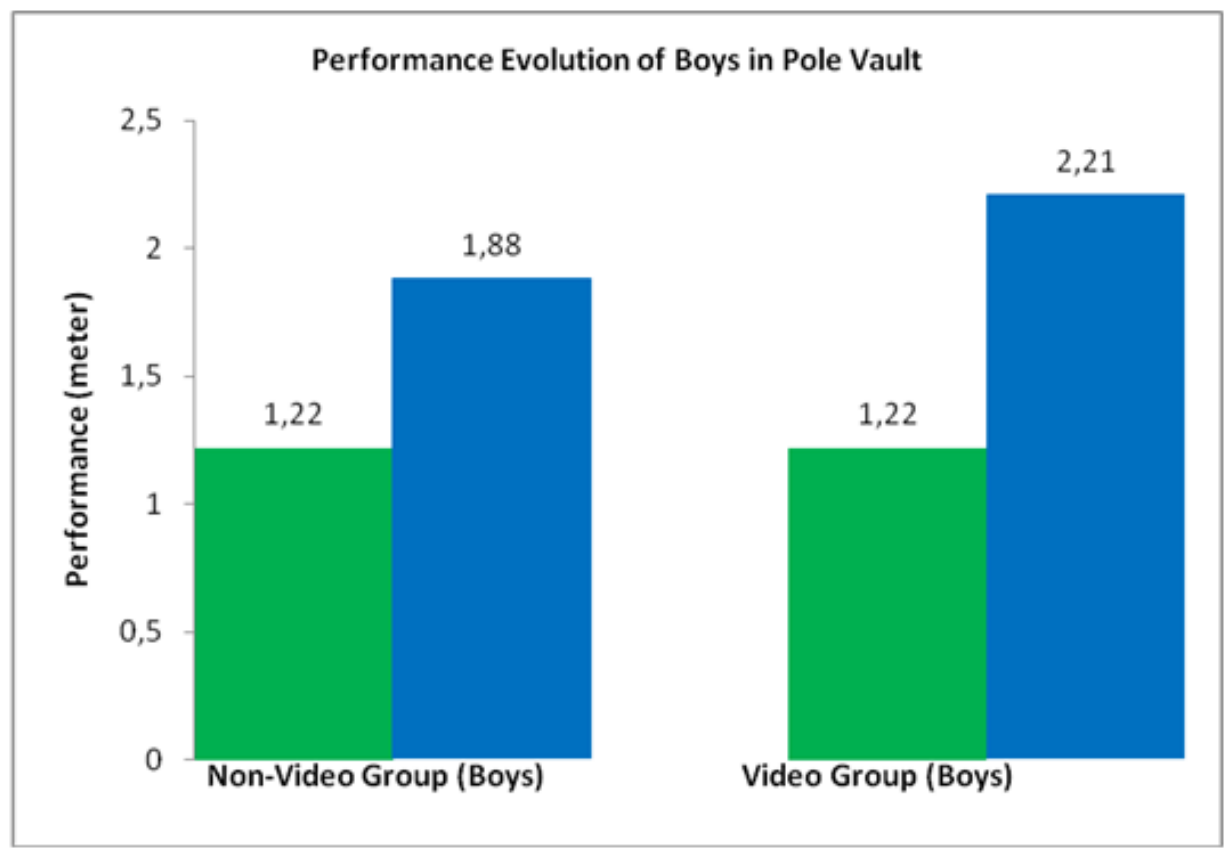

Figure 5. Evolution of motor performance in pole vault of young boys 
4.2. Statistical analysis of the evolution of the performance of the non-video video group

Table 4: Student's test and the effect of the video on the progression of student performance $(\mathrm{N}=44)$

\begin{tabular}{|c|c|c|}
\hline & Initial Evaluation & Final Evaluation \\
\hline Video Class & 1.13 & 2.00 \\
\hline Non-Video Class & 1.13 & 1.76 \\
\hline \multirow{2}{*}{ T-Student } & $t=0.352$ & $t=4.269$ \\
\hline & $p=0.728$ & $p<0.001$ \\
\hline Video Group & 1.22 & 2.21 \\
\hline Girls & 1.03 & 1.77 \\
\hline \multirow{2}{*}{ T-Student } & $t=3.929$ & $t=7.145$ \\
\hline & $p<0.005$ & $p<0.001$ \\
\hline Non-Video Group & 1.22 & 1.88 \\
\hline \multirow{3}{*}{ T-Student } & 1.03 & 1.63 \\
\hline & $t=3.311$ & $t=8.216$ \\
\hline & $p=0.01$ & $p<0.001$ \\
\hline
\end{tabular}

The Student's test in Table 4 tells us that in the first diagnostic evaluation the result is insignificant with $(\mathrm{t}=$ $0.352, \mathrm{p}=0.728)$, which is normal in the sense that we checked the homogeneity between groups and the cycle has not started. Very normally, the averages of the two groups are almost identical. On the other hand, at the end of the cycle, the Student's test is significant with $(\mathrm{t}=4.269, \mathrm{p}<0.001)$, it confirms the hypothesis that the use of video in the context of computer technology coupled communication of regulations verbal and non-verbal (gestural) by an expert speaker is a source of motor progression for students.

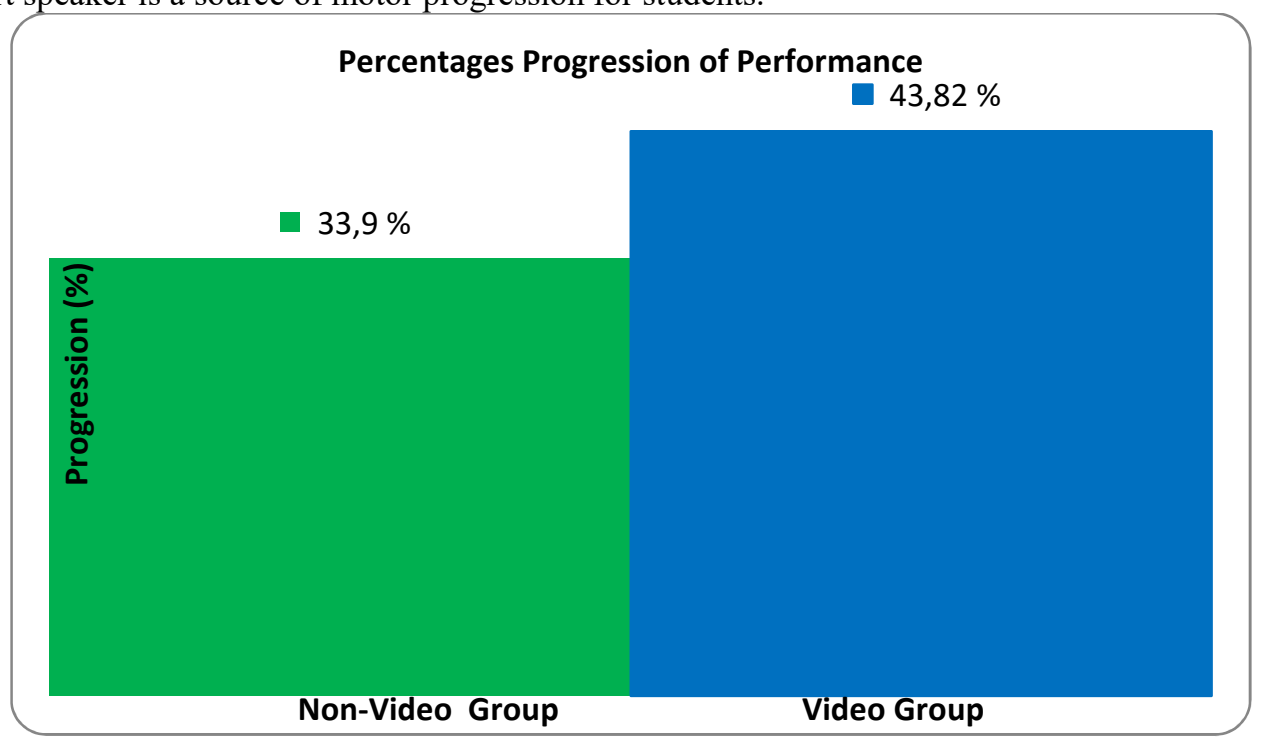

Figure 6. Percentage Progression of Motor Performance in Pole Vault

We are now interested in the various progressions within each group. Thus, it is a non-video group that benefited from verbal and gestural regulations from the teacher and a video group that benefited from verbal and gestural regulations from the same teacher in the discipline, as well as being able to view the performance at the same time corrected on a control screen. On the one hand, we note the percentage difference in progression that exists in each class between girls and boys. On average, boys and girls in the video category grew by more than $(12 \%$ and $9 \%$ ), respectively, compared to their peers in the non-video group (see Figure 6).

The crossed results of the two classes will allow us to know if the use of a video artifact is a source of motor progression. This is achieved by combining the verbal and gestural corrections while relying on the video images broadcast before the teacher and the student. We will therefore analyze the results with the progression indices of these two classes sorted by percentage. Thus, in this teaching in the form of oriented jumping tasks, a certain differentiation of pupils according to their level and gender position appears. Students do not invest in their tasks in the same way, as long as these subjects were judged to be of equivalent level by the teacher at the beginning of the cycle. It should be noted, however, that the observations made can not be minimized to a limited differentiation between girls and boys, since pupils (girls and boys) succeed to varying degrees in responding to the teacher's orientations and their interests in the task, during the pole vault cycle.

The results also highlight that the use of the video associated with the computer tool attached to the verbal and non-verbal regulations of the teacher of the discipline promotes student learning. All students in the video group increased by more than $43 \%$ and their percentage increases are all higher than the percentages of their peers 
in the non-video group 33\% (see Table 3 and Figure 3). Also, the difference is significant between the two groups of young boys (video and non-video) $(\mathrm{p}<.001)$. Tables 1,4 and Figure 4 present the results of boys. We see here that the results are also different. However, from the results it was observed that the boys in the video group progressed (from $40 \%$ to $53 \%$ ) as much as the non-video group (from $14 \%$ to $47 \%$ ) with a significant difference $(\mathrm{p}=.001)$ in Table 4 . While the difference and very significant $(\mathrm{p}<.001)$ between the progression of the girls' video group (from $29 \%$ to $51 \%$ ) compared to the non-video group of girls (from $12 \%$ to $47 \%$ ), (see Tables 2,4 and Figures 4, 5 and 6). Thus, Pole vault learning using video takes precedence over the progression of non-video group learning during a pole vault cycle.

These different observations and this cross-over of roles with video and non-video group classes show us very clearly the contribution of using a video artifact and the computer tool. Of course, entrusted to a specialist in the activity of pole vault (athletics), the progress will be even stronger. But what must be remembered is that video and imaged teaching still seems effective when put in either the hands of a specialist or non-specialist in the pole vault discipline.

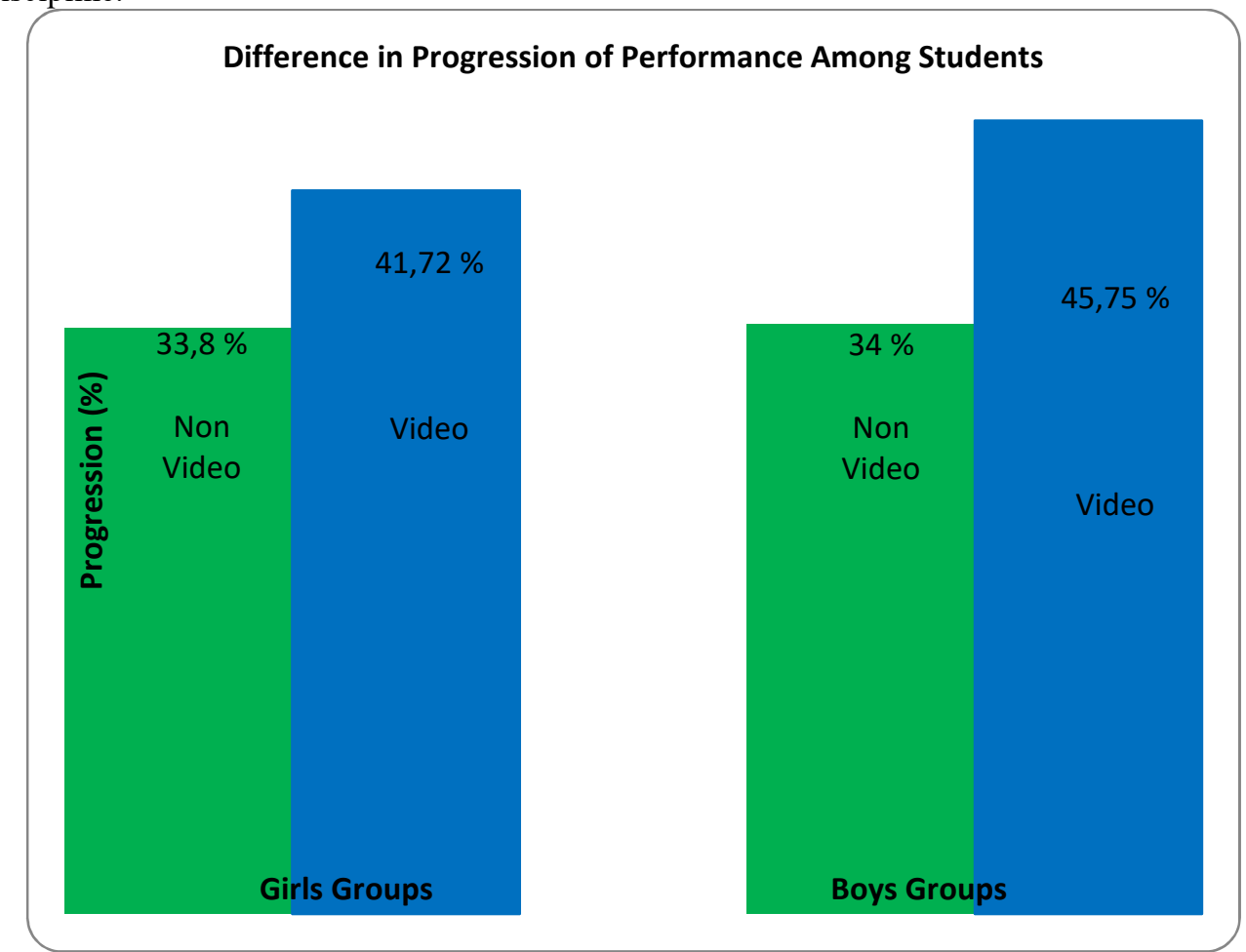

Figure 7. Differentiated Progression of Pole Vault Performance for Girls and Boys

\section{Discussion}

\subsection{Analysis of the Computer Communication Technology (CCT) function on teaching}

Videotape feedback in the educational classroom has been a widely used for teaching and assessment to encourage certain behavioral changes in children, like the use of instructions for video self-modeling (Buggey, T., 2007). Among the difficulties that we expected were those due to the students' confrontation with their own image in the presence of the video camera. But we found them not very busy with the presence of the camera; their attitude was the same in all the educational situations put in place. We do not think it should be concluded that the use of video will no longer interfere with students. So, reflecting on video feedback as a tool for learning skilled movement (Cassidy, Stanley \& Bartlett, 2006). We must be cautious and take into account all the data related to the context. During our reading, it was often question of autoscopy problems but with high school classes, college or high school. A teenager is often much more motivated by his motor image that develops from one session to another. At certain stages, we agree that the adolescent can not bear to be criticized with his own image and to be judged less before and by the other students in his class and is sometimes hesitated to intervene in action. However, in our implementation with the two classes, there was never any question of collective feedback. The work with the video was done only in separate workshop and individually with each student; it already greatly reduced the anxiety of the students. Potdevin et al. (2018) add that video feedback can be used in physical education to support novice learning in gymnastics and motivate students. The fact that the tools were used unambiguously gave students the feeling that the camera was part of the work equipment that helps them progress and they adapt more easily. Thus, images and other computer communication technologies (CCT) present accessories (video, computer, computer software) very functional in learning tasks to become traditions. Not only should the use of CCT not be too 
problematic for PES teachers, but for early use they will gain a better understanding of the use of CCT. Palao et al. (2015) show in their study the impact of video technology on student performance in physical education

\subsection{Analyzing effects of video feedback}

At the end of different results that we obtained with the two classes that participated in our experiment, we can only signify the positive effects of the video feedback on the motor progressions of the pupils. The effect of integrating video-based feedback into a teaching games was for understanding activity unit (Harvey \& Gittins, 2014). In line with this analyze Aranha and Gonçalves (2012) highlight the importance of video-feedback and instruction in a study that involves the apprenticeship of a sport technical skill of fosbury flop in physical education lessons. It should be noted, however, that all video feedback was paired with verbal regulations from the teacher. And the fact of these regulations allowed the subject to concentrate on the elements of the task to be corrected. Without a doubt, a subject who is not used to being seen on the screen could be distracted by the image if the verbal regulations did not come to refocus on the main function of the CCT and its video feedback. We find, therefore, that video feedback is effective on teenage students having an age that allows them to perceive the image message. So, we think, based on the results obtained, that young beginners are able to use their visual analysis capacity effectively to perceive the information that video feedback puts forward. The quality of the verbal regulations that will accompany it will then be very important, but as long as the attention of the subjects is focused on specific elements of the action, that the instructions are targeted and that the advice given correlates with their potential engines, there is no reason that the student is not able to manage and interpret the video feedback. It seems that the tool is interesting to the point of trying to also perceive the errors to anticipate the regulations of the teacher or the speaker during their verbal corrections. Let's not forget that it is the verbal regulations associated with video feedback that are the source of important motor progressions (Potdevin et al., 2018; Rabardel, 1995). And sometimes, students themselves could correct themselves. What I think is important is the students' perception of their mistakes through video footage. To understand his mistakes and to verbalize them is to tend towards selfregulation, in that the intervention of the CCT is anyway a success.

\subsection{Analysis of the relationship between gender difference and motor performance}

Studies have shown that the gender difference in class is an assurance of student engagement in pole vaulting and other physical and sport activities (Derbali et al., 2018b; Davisse, 2010; Bui-Xuân 1989). Despite this, the results of our research show that boys' performance was higher than that of girls with a significant difference in video and non-video groups respectively $(\mathrm{t}=7.145, \mathrm{p}<.001, \mathrm{t}=8.216, \mathrm{p}<.001)$, while the increase in motor performance is high and exceeds $34 \%$ for girls and is over $45 \%$ for boys. We note that the positive evolution of boys' motor performance is better compared to that of girls. Interpretations of different research in PAS show that boys progress more than girls (Coupey, 1995) and that they are more reluctant than girls to go beyond stereotypes. Many studies done on PAS assessment show that girls get lower averages than boys (Derbali et al., 2015a; Lentillon, 2005). In the contrary, there is a study indicating that boy and girl presented quite different behavior in multiple sets of weight exercises, and girl presented a more stable performance and a higher endurance ability to the fatigue as well (Salvador et al., 2009). Whereas, teachers' perceptions of physical education content and influences on gender differences as if attitudes and pedagogical practices are marked by implicit sexism (Castejón \& Giménez, 2015). Finally, although more formal, girls are less active than boys in the field of motor skills (Davisse, 2010). The consequences of the research indicate that there are two categories of teachers. Those who provide a stereotypical view of roles conceded that girls are rather passive, active boys, with girls withdrawing in some activities, boys in others. Those for whom the gender variable is not satisfied to develop differences in results. Many teachers therefore feel it is essential to modulate students' demands according to gender, while others believe it is better to have the same requirements for all. Student performance in the assessments shows that girls perform worse than boys at the beginning of the cycle and at the end of the pole vault cycle. In this regard, the results corroborate with those of Cleuziou (2000) who found that it is the most taught PAS that are particularly discriminating for girls, and even more the combination of activities. Why then continue teaching in the same curriculum (gymnastics, volleyball and athletics), while the results show that it is in these activities that girls perform the least good results? The bodily education of the learner still goes through the physical practice fundamentally sports. At the end of these observations, prospects can be envisaged. How to find a compromise between the recognition of the differences of girls and boys and at the same time the recognition of equal treatment in the scales in pole vault? The innovation prospectus undertaken by Bergé et al. (2001) initiates proposals creating benchmarks to mitigate this gap. Thus, it is obviously not a question of programming exclusively feminine PAS (Davisse, 2000), but rather of finding a balance between PAS. Studies have shown that gender difference is a guarantee of student engagement in physical activity: Pole vaulting, football, rugby, judo, are accessible to girls and boys (Kirk et al., 2018; Derbali et al., 2017b, 2015b; Davisse, 2010; Bui-Xuân, 1989). Globaly, video technology has impact on student performance in physical education (Palao et al., 2015). 


\section{Conclusion}

We want to investigate the video device during a school pole vault cycle. Recalling that, the objective of this study is to facilitate and improve motor learning among students during a pole vault cycle by respecting the difference between girls and boys. The purpose is to determine the effect of this video artifact and the computerized communication tools (CCT) on learning through a comparative study between one group that used the video and another without using the observation of video and is limited solely to vocabularies language and gestural activity.

Our research was oriented towards the replication of the computer communication technology (CCT) device under identical conditions to validate the desired results with a cross-placement of the video and computer device with two high school classes by entrusting to each the same teacher, a video group of the first class and another non-video belonging to the other class. Through this experiment, we have been able to conclude that the use of the CCT and precisely of the video image artifact, was source of progression of the motor learning for the large majority of the pupils with percentages of progression which vary between $(12 \%$ and $53 \%)$. When the verbal regulations accompanying the video procedure were made by an EPS teacher the progression results were significant in showing the effect of the CCT on improving performance. What to say then, for impeccable results that could be obtained in the same conductions but with a teacher specializing in pole vaulting. These results were very significant in showing a significant improvement in motor behavior as well as self-regulating performance and error correction. To this extent, we find that the results show that the performance of all students increases significantly when they benefit from verbal and gestural regulations based on sufficiently analyzed video sequences. It seems clear that students, thanks to video feedback, are able to construct a more precise mental representation of their performances, which, in terms of motor learning, gives them a better regulation of their actions and therefore a greater success in the progression of their performances in pole vaulting. This echo has expressed that repetitive use of video feedback is essential to improve performance. We can, thus, confirm our first hypothesis of departure, the device CCT is well source of motor progressions for high school pupils in cycle of vault. Although both teachers mark a significant effect of the use of CCT on the learning progress of their students, we find a gap in measurable performance (the height of the jump) between girls and boys. This gap could be related to three main factors. For a first point, we think that the physical and morphological qualities (height and weight), could influence the performance of the learner. For a second point, the intervention of the boy could be more energetic and is rich in technicality than the less active girls. Finally, we note that the teacher showed a tendency in his teaching towards sportivization. Hence the research, in conclusion, to optimize the measurable performance (jump to the highest possible). This, of course with the search for improved skills and motor skills through the practice of pole vault for girls and boys in the educational environment. In addition, the intervention of the CCT device technique allows students to view their performances in the seconds preceding them. They perceive that they still have in mind their postures and their actions. It also allows a verbal and gestural correction with other teacher analyzes in the short-term memory of students, this phase of memory very receptive which facilitates the installation of learning. And the various results and analyzes made in this paper show that students who have benefited from these educational situations imaged video all increased on average by $44 \%$, where other students were up $33 \%$. In addition, it is important to remember that information feedback by computer and imaged communication technology was individual. Indeed, the teacher incorporates into its educational project the tool and its use by associating meanings and teachings of, then it will target its regulations on content that images will illustrate and justify. Moreover, this explains his desire and enthusiasm to form and the best use of the device that was their motivation in pole vault cycle. Given these results, with the experience of implementation in a real professional context, we can extrapolate that it is possible to set up a computer-video artifact as we used in the sessions teaching-learning of a pole vault cycle.

Finally, for us, it is clear that this new instruction comes to serve the didactics of physical activity is sports. Here, CCT is not seen as an end in itself but as a means of acquiring the motor skills of new knowledge among others and should not exclude other forms and other teaching aids. The variation of the material and its ease of use which make currently, the used tools of CCT are supports to the setting up of educational situations in physical education and sport. We could also imagine the design of a video-computer-type educational support accompanied by didactic scripts. We have seen in individual analyzes that all students, without exception, have made much progress over the cycle. Finally, a call directed to institutions to develop their tools for transforming knowledge.

\section{References}

[1] Aranha, Á.C., \& Gonçalves, F.J. M. (2012). The importance of video-feedback and instruction. Journal of Physical Education and Sports Management 3 (1). DOI: 10.5897/JPESM11.010

[2] Bailey, R. (2018). Sport, physical education and educational worth. Educational Review 70 (1): 51-66 https://doi.org/10.1080/00131911.2018.1403208

[3] Bandura, A. (1967). Behavioral psychotherapy. Scientific American 216 (3): 78-86.

[4] Bastianello, M. R., Pacico, J. C., \& Hutz, C. S. (2014). Otimismo, autoestima e personalidade: estudos de adaptação e validação brasileira do Revised Life Orientation Test (LOT-R). Psico-USF (19): 523-531. 
[5] Bonney E, Jelsma LD, Ferguson GD, Smits-Engelsman BCM (2017) Learning better by repetition or variation? Is transfer at odds with task specific training? PLoS ONE 12(3): e0174214. https://doi.org/10.1371/journal.pone.0174214

[6] Bosse, M-L. (2015). Learning to Read and Spell: How Children Acquire Word Orthographic Knowledge. Child Development Perspectives 9 (4): 222-226. https://doi.org/10.1111/cdep.12133

[7] Boyer E (2009). Video Modeling by Experts with Video Feedback to Enhance Gymnastics Skills. J. Appl. Behav. Anal. 42 (4): 855-860.

[8] Buggey, T. (2007). A Picture is Worth...Video Self-Modeling Applications at School and Home. Journal of Positive Behavior Interventions 9 (3): 151-158.

[9] Bui-Xuân, G. (1989). «Pédagogie de l'EPS et /ou didactique des APS. Enjeux et objectifs », in Méthodologie et didactique de l'EPS, Clermont-Ferrand, AFRAPS, $\mathrm{n}^{\circ} 53$.

[10] Campbell, D. E. (2010). Gender and Schools. Pearson Allyn Bacon: Prentice Hall.

[11] Canedo, M D-M. F., Rodríguez, C. F., Fernández, B. R. \& Valle Arias, A. (2018). Defensive pessimism, selfesteem and achievement goals: A person-centered approach. Psicothema 30 (1): 53-58. doi:10.7334/psicothema2017.199

[12] Carr, D. (2010). On the Moral Value of Physical Activity: Body and Soul in Plato's Account of Virtue. Sport, Ethics and Philosophy 4 (1): 3-15. DOI: 10.1080/17511320903264222

[13] Carroll, W. R., \& Bandura, A. (1982). The role of visual monitoring in observational learning of action patterns: Making the unobservable observable. Journal of Motor Behavior (14): 153-167.

[14] Cassidy, T., Stanley, S., \& Bartlett, R. (2006). Reflecting on Video Feedback as a Tool for Learning Skilled Movement. International Journal of Sports Science \& Coaching 1 (3): 276-288.

[15] Castejon, F.J., \& Gimenez, F.J (2015). Teachers' perceptions of physical education content and influences on gender differences. Motriz: rev. educ. fis. 21 (4): 375-385. http://dx.doi.org/10.1590/S198065742015000400006

[16] Chen, Tan Zhang, Stephanie L. Wells, Ray Schweighardt, \& Catherine D. Ennis (2017). Impact of Teacher Value Orientations on Student Learning in Physical Education. J Teach Phys Educ. 36 (2): 152-161.

[17] Conversano, C., Rotondo, A. Lensi, E., Della Vista, O., Arpone, F. \& Antonio Reda, M. (2010). Optimism and Its Impact on Mental and Physical Well-Being. Clinical Practice \& Epidemiology in Mental Health (6): 25-29.

[18] Coupey, S. (1995). Pratique d'EPS au CP et différence de performance entre les filles et les garçons. Revue Française de pédagogie (110) : 37-50.

[19] Davisse, A. (2010). «Filles et garçons en EPS : différents et ensemble ? », Revue française de pédagogie (171) : 87-91

[20] Derbali, C. \& Naceur, A. (2009). Relationships between physical self-perception and physical selfdetermination: prediction of physical self-efficacy. In "Cognition, Emotion \& Motivation : Percept Concept - Decision ...Applications to learning activities”. ISBN 978-9973-13009-9.

[21] Derbali, C. (2010). Perception, Motivation et Autonomie Concept de soi et apprentissage : Apprentissage en Éducation Physique. Éditions Universitaire Européenne - $\mathrm{N}^{\circ}$ ISBN 10: 6131533989/ISBN 13: 9786131533983

[22] Derbali, C., Ben Jannet, Z. \& Elloumi, A. (2015a). Physical self-perception and sport's activity applied in physical education context: The self-efficacy of achievement performance. International Journal of Advanced Sport Sciences Research 3 (1): 482-497.

[23] Derbali, C., Elloumi, A., \& Matoussi, F. (2015b). Didactics of Physical Education: The Case of Motivational students Profiles in Pole Vaulting Performance. Creative Education 6 (12) http://dx.doi.org/10.4236/ce.2015.612136

[24] Derbali, C., Elloumi, A., \& Matoussi, F. (2017a). The Need to Learn according to Psycho-Didactic Approach: Self-Determination and Student's Performance in Physical Education Realm. Creative Education (8): 1155 1171. https://doi.org/10.4236/ce.2017.87083.

[25] Derbali, C., Elloumi, A., \& Matoussi, F. (2017b). Reflections and Conceptions Analysis of the Neosphere's Actors on Teaching Pole Vault Activity throw Physical Education Program. International Research Journal of Curriculum and Pedagogy 3 (2): 52-58.

[26] Derbali, C., Elloumi, A., \& Matoussi, F. (2018b). Curriculum Method Grounded on Didactic Engineering to Expertise Physical Education Program Proposal. Journal of Education and Practice 9 (31): 49-59

[27] Derbali, C., Matoussi, F., \& Elloumi, A. (2017c). Motivational Climate and Skills Development in Physical Education: A Pilot Study Examining Physical Activity Behavior in an Educational Environment. Journal of Information Research and Review 4 (12): 4756-4763.

[28] Derbali, C., Naceur, A. \& Masmoudi, S. (2008). Effet du Concept de soi sur le processus d'apprentissage d'une activité sportive: cas du triple saut. In A., Naceur \& S., Masmoudi (Eds.), Cognition, Emotion \& Motivation : Intégrer ... Mieux expliquer la performance. Éditions CNIPRE, Tunis ISBN 9973-13-011-2. 
[29] Derlon, A. (1989). EPS, APS et nouvelles pratiques. Une enquête dans l'Académie de Bordeaux. In Bui Xuan, G. (sous la direction de). Méthodologie et didactique de l'EPS. Clermont Ferrand, AFRAPS, pp: 107-118. doi: [10.1123/jtpe.2016-0027]

[31] Douglas E.Y. \& Richard A.S. (1992): Augmented Kinematic Feedback for Motor Learning, Journal of Motor Behavior 24 (3): 261-273. http://dx.doi.org/10.1080/00222895.1992.9941621

[32] Edwards, C. P., Knoche, L. \& Kumru, A. (2003). "Socialization of Boys and Girls in Natural Contexts" Faculty Publications, Department of Psychology, (613). http://digitalcommons.unl.edu/psychfacpub/613

[33] Elias, M. J. (1991). An action research approach to evaluating the impact of a social decision-making and problem-solving curriculum for preventing behavior and academic dysfunction in children. Evaluation and Program Planning 14 (4): 397-401.

[34] Guadagnoli, M.A., Holcomb, W., \& Davis, M. (2002). The efficacy of video feedback for learning the golf swing. Journal of Sports Sciences (20): 615-622.

[35] Guadagnoli, M.A., McDaniels, A., Bullard, J., Tandy, R.D., \& Holcomb, W.R. (2001). The influence of video and verbal information on learning the golf swing. In P.R. Thomas (Ed.), Optimising performance in the golf swing (pp. 94-103). Brisbane: Australian Academic Press.

[36] Harvey, S., \& Gittins, C. (2014). Effects of integrating video-based feedback into a Teaching Games for Understanding soccer unit. Agora Para la Educación Física y el Deporte (16): 271-290.

[37] Hastie, Peter A. \& Wallhead, Tristan L. (2015). Operationalizing physical literacy through sport education. Journal of Sport and Health Science 4 (2): 132-138. http://dx.doi.org/10.1016/j.jshs.2015.04.001

[38] Kirk, D., Lamb, C. A., Oliver, K. L., Ewing-Day, R., Fleming, C., Loch, A. and Smedley, V. (2018). Balancing prescription with teacher and pupil agency: spaces for manoeuvre within a pedagogical model for working with adolescent girls. Curriculum Journal, 29 (2): 219-237. doi:10.1080/09585176.2018.1449424

[39] Lentillon, V. (2005). Privation, justice, inégalités: perceptions différenciées chez les filles et les garçons au niveau des notes et du soutien obtenus en EPS ? (Deprivation, justice, inequalities: are perceptions differentiated among girls and boys on the level of grades and supports obtained in PE?). In G. Cogerino (Ed.), Filles et garçons en EPS. Paris: Ed. Revue EPS, pp. 181-197.

[40] Léziart, Y. (1997). Savoir savant et transposition didactique. STAPS 42 : 59-70.

[41] Magill, R.A. (1993). Motor learning: Concepts and applications (4th ed.). Dubuque, IA: Brown and Benchmark.

[42] Mayorga-Vega, D., Martínez-Baena, A. \& Viciana, J. (2018). Does school physical education really contribute to accelerometer-measured daily physical activity and non sedentary behaviour in high school students? Journal of Sports Sciences 36 (17): 1913-1922. https://doi.org/10.1080/02640414.2018.1425967

[42] Moate, R. M., \& Cox, J. A. (2015). Learner-centered pedagogy: Considerations for application in a didactic course. The Professional Counselor (3) 379. doi:10.15241/rmm.5.3.379

[43] Norem, J., \& Cantor, N. (1986b). Defensive pessimism: Harnessing anxiety as motivation. Journal of Personality and Social Psychology (51): 1208-1217.

[44] Palao, J.M., Hastie, P.A., Cruz, P.G., \& Ortega, E. (2015). The impact of video technology on student performance in physical education. Technology Pedagogy and Education 24 (1): 51-63. DOI: 10.1080/1475939X.2013.813404

[45] Parlebas, P. (1991). « didactique et logique interne des APS », Paris, revue EPS n²28. Parlebas P, dossier EPS n ${ }^{\circ} 4$

[46] Parlebas, P. (1999). Jeux, sports et sociétés. Lexique de praxéologie motrice, Paris, INSEP-Publications.

[47] Poggi-Combaz M-P. (2002a). «Distribution des contenus d'enseignement en EPS au collège selon les caractéristiques sociales du public scolaire : des différences non aléatoires », Revue Française de Pédagogie (139): 53-69.

[48] Potdevin, F., Vors, O., Huchez, A., Lamour, M., Davids, K., \& Schnitzler, C. (2018). How can video feedback be used in physical education to support novice learning in gymnastics? Effects on motor learning, self- assessment and motivation. BMC Med Educ. 15 (22): 559-574. https://doi.org/10.1080/17408989.2018.1485138

[49] Rabardel, P. (1995). Les hommes et les technologies, une approche cognitives des instruments contemporains. Armand Colin, Paris.

[50] Salmoni AW, Schmidt RA, Walter CB. (1984). Knowledge of results and motor learning: A review and critical reappraisal. Psychological Bulletin (95): 355-386.

[51] Salvador EP, Ritti-Dias RM, Gurjão ALD, Avelar A, Pinto LG, Cyrino ES. Effect of eight weeks of strength training on fatigue resistance in men and women. Isokinet Exerc Sci. (17): 101-106.

[52] Schmidt RA, Lee TD. (1999). Motor control and learning: A behavioral emphasis. 3rd ed. Human Kinetics; Champaign, IL.

[53] Schmidt, R. (1993). Apprentissage moteur et performance, Paris, Vigot.

[54] Solmon, M. A. (2015). Optimizing the Role of Physical Education in Promoting Physical Activity: A Social- 
Ecological Approach. Resarch Qarterly Exercise Sport 86 (4): 329-337. 10.1080/02701367.2015.1091712.

[55] Spaaij, R., Oxford, S., \& Jeanes, R. (2016). Transforming communities through sport? Critical pedagogy and sport for development. Sport, Education and Society 21 (4): 570-587.

[56] Stamarski, C.S. \& Son Hing, L.S. (2015). Gender inequalities in the workplace: the effects of organizational structures, processes, practices, and decision makers' sexism. Front Psychol. (6):1400. doi: 10.3389/fpsyg.2015.01400.

[57] Swinnen, S.P. (1996). Information feedback for motor skill learning: A review. In H.N. Zelaznik (Ed.), Advances in motor learning and control (p. 37-65). Champaign, IL: Human kinetics.

[58] Young, D.E., \& Schmidt, R.A. (1992). Augmented Kinematic Feedback for Motor Learning. Journal of Motor Behavior 24 (3): 261-273. http://dx.doi.org/10.1080/00222895.1992.9941621. 